\title{
Changes of Quality of Semen after Swim up Method during Intrauterine Insemination: A Single Centered Experience in Dhaka City
}

\author{
Shafeya Khanam¹, MoriumFaruque Shati², Muqsuda Ashraf Shuvro², \\ Sharmin Ahmed ${ }^{4}$, Trifa Obayed ${ }^{5}$, Tahamina Khanum ${ }^{6}$ \\ ${ }^{1}$ Associate Professor, Department of Gynaecology\& Obstetrics, Faridpur Medical College, Faridpur, Bangladesh; ${ }^{2}$ Professor \\ of Gynaecology\& Obstetrics, LabAid Hospital, Dhaka, Bangladesh; ${ }^{3}$ Consultant (Gynaecology\& Obstetrics), LabAid \\ Hospital, Dhaka, Bangladesh; ${ }^{4}$ Medical Consultant, Bangladesh Council of Scientific and Industrial Research, Dhaka, \\ Bangladesh; ${ }^{5}$ Honorary Medical Officer, Department of Gynaecology\& Obstetrics, Institute of Child \& Mother, \\ Matuail, Dhaka, Bangladesh; ${ }^{6}$ Assistant Professor, Department of Gynaecology \& Obstetrics, Enam Medical \\ College, Savar, Dhaka, Bangladesh
}

[Received: 21 July 2017; Revised: 6 August 2017; Accepted: 11 October 2017; Published: 1 January 2018]

\begin{abstract}
Background: Quality of semen is very important during intrauterine insemination. Objectives: The purpose of the present study was to observe the changes of quality of semen after swim up method during intrauterine insemination. Methodology: This analytical type of cross-sectional study was carried out at a private infertility centre (Central Hospital Limited, Dhaka) in Dhaka city of Bangladesh from January 2012 to December 2017 for a period of 6 years. Infertile couples who already had undergone natural cycles of super-ovulation for six months or whose duration of infertility was more than one year were included. Semen samples were collected by the process of masturbation in semen production room after three days of abstinence in sterile, labelled container. After production all samples were placed in an incubator at 37 degrees Celsius for 30 minutes for liquefaction. Routine semen analysis was performed using World Health Organizations' (WHO) semen analysis criteria. Then the samples were randomly assigned to be processed either with swim-up or density-gradient procedure. Result: A total number of 789 male respondents were recruited for this study. The mean age with SD of the study population was $28.96 \pm 5.382$ with the range of 19 to 46 years. The mean changes of sperm concentration before and after swim up method was $52.70 \pm 42.88$ with the $95 \%$ confidence of 49.58 to $55.82(\mathrm{p}=0.000)$. The mean changes of sperm motility before and after swim up method was $29.03 \pm 14.849$ with the $95 \%$ confidence of 30.11 to $27.95(\mathrm{p}=0.000)$. The mean changes of sperm morphology before and after swim up method was $23.96 \pm 11.328(\mathrm{p}=0.000)$. Conclusion: There is a significant changes of quality of semen after swim up method during intrauterine insemination. [Journal of National Institute of Neurosciences Bangladesh, 2018;4(1): 54-57]
\end{abstract}

Keywords: Changes; Quality of Semen; Swim up Method; Intrauterine Insemination

Correspondence: Dr. ShafeyaKhanam, Associate Professor, Department of Gynaecology\& Obstetrics, Faridpur Medical College, Faridpur, Bangladesh; Email: shafeyakhanam@gmail.com; Cell no.: +8801711158720

Conflict of Interest: The authors declare that they have no competing interest.

Contributionsto Authors': Khanam S, Shati MF, Shuvro MA were involved in the procedure and collect the data. Ahmed S, Obayed T, Khanum T were involved the reporting, data analysis and writing the manuscript.Khanam S, Shati MFwere revised the manuscript. All the authors have read and approved the final version of the manuscript.

Funding: This research project was not funded by any group or any institute on.

How to cite this article: Khanam S, Shati MF, Shuvro MA, Ahmed S, Obayed T, Khanum T. Changes of Quality of Semen after Swim up Method during Intrauterine Insemination: A Single Centered Experience in Dhaka City. Journal of National Institute of Neurosciences Bangladesh, 2018;4(1): 54-57

Copyright: (02018. Khanam et al. Published by Journal of National Institute of Neurosciences Bangladesh. This article is published under the Creative Commons CC BY-NC License (https://creativecommons.org/licenses/by-nc/4.0/). This license permits use, distribution and reproduction in any medium, provided the original work is properly cited, and is not used for commercial purposes.

\section{Introduction}

Infertility is a serious concern affecting many couples ${ }^{1}$. It can cause the loss of the status within the family and community. It has been estimated that about $20 \%$ men could suffer worldwide from fertility problems ${ }^{1}$. The rising level of male infertility has become a serious fear in the field of public health ${ }^{2}$. Fertility has been the main study of civilization since immemorial time but the progression is rather sluggish. Infertility can be defined as the incapacity to fulfill pregnancy after 12 months of 
unprotected $\operatorname{sex}^{3}$. Global data confirms that male are to be responsible either fully or partially for 35 to $40.0 \%$ cases of infertility, while female partners are responsible for 35 to $40 \%$ and the remaining 20 to $30 \%$ is the combination of couples and a small percentage of unknown causes ${ }^{2}$.

In developing countries like Bangladesh, patterns of infertility are quite different from those in developed countries and the incidence of preventable infertility is much higher in developing countries ${ }^{4}$. Many cases of male infertility require sophisticated and expensive treatment. Therefore, the addressing the issue of male infertility appears to be one of the priority tasks of infertility programmes in the developing countries; Bangladesh is not an exception. Intrauterine insemination (IUI) is the first-line assisted reproduction treatment (ART) modality for infertile couples ${ }^{5}$. Since its introduction, more and more sophisticated techniques were developed for improvement in sperm recovery and separation of functionally competent spermatozoa ${ }^{6}$. Although none of the developed techniques follow the ideal requirement, but they are still used depending on the quality and the amount of ejaculate ${ }^{7}$. In this context this present study was undertaken to observe the changes of quality of semen after swim up method during intrauterine insemination.

\section{Methodology}

This analytical type of cross-sectional study was carried out at a private infertility centre (Central Hospital Limited, Dhaka) in Dhaka city of Bangladesh. This study was carried out from January 2012 to December 2017 for a period of 6 years. Non-probability convenient sampling technique was applied and was comprised infertile couples. Infertile couples who already had undergone natural cycles of super-ovulation for six months or whose duration of infertility was more than one year were included. Similarly, cases where hysterosalpingography (HSG) showed patent fallopian tubes or husband semen analysis demonstrated sperm count of $>5$ million were also included. Cases in which the age of woman was $>45$ years, fallopian tubes were blocked or sperm concentration was $<5$ million were excluded. Also excluded were cases which showed follicular count of more than 10 in a cycle as they were associated with risk of ovarian hyperstimulation syndrome (OHSS), in which cycles were converted into natural cycles. After informed consent, all couples were inquired about, age, duration of infertility, type of infertility, indication of IUI and the number of previous IUI attempts. Semen samples were collected by the process of masturbation in semen production room after three days of abstinence in sterile, labelled container. Written as well as verbal instructions were given for the production of sample to get good recovery of semen sample. After production all samples were placed in an incubator at 37 degrees Celsius for 30 minutes for liquefaction. Routine semen analysis was performed using World Health Organizations' (WHO) semen analysis criteria like sperm concentration $>15 \times 106$ spermatozoa/ml, total sperm count $39 \times 106$ per ejaculate or more, motility $35.0 \%$ or more with forward progression, and morphology $14 \%$ or more with normal form. Sperm motility was assessed by microscope appraisal of 200 spermatozoa from different fields. Mecklar counting chamber (SEFI medical instruments) was used for counting of spermatozoa. Then the samples were randomly assigned to be processed either with swim-up or density-gradient procedure. Before preparation, all media were incubated at $37^{\circ} \mathrm{C}$ for 15 minutes. After liquefaction, $1 \mathrm{ml}$ of semen was placed in $15 \mathrm{ml}$ labelled conical tube (BD Falcon) and $2 \mathrm{ml}$ of medium (GMOP-PLUS, Vitrolife) was overlaid on the semen sample. The tube was incubated at $37^{\circ} \mathrm{C}$ for 45-60minutes to allow progressively motile sperm to swim into the overlaid medium. Taking care not to disrupt the interface, the overlaid medium was then collected and mixed with $2-3 \mathrm{ml}$ of medium (GMOP-PLUS) and centrifuged at $300 \mathrm{~g}$ for 10 minutes. Then the supernatant was removed and the pellet was re-suspended in $0.3-1 \mathrm{ml}$ of fresh medium (GMOP-PLUS, Vitrolife). SPSS 21 was used for data analysis. Descriptive statistics like mean and standard deviation (SD) were calculated for pre- and post-preparative sperm count and motility for both days while frequency and percentage for successful outcome and fecundity. Pre- and post-preparative sperm count were compared for statistical difference using Mann-Whitney U test for each procedure while Fisher's exact test was applied to measure the difference between conceived and non-conceived group for parameters of success. $\mathrm{P}<0.05$ was considered statistically significant.

\section{Results}

A total number of 789 male respondents were recruited for this study. Majority were in the age group of 20 to 30 years which was $449(56.9 \%)$ male followed by more than 30 years and less than 20 years which were $306(38.8 \%)$ cases and 34(4.3\%) cases respectively. The mean age with SD of the study population was $28.96 \pm 5.382$ with the range of 19 to 46 years (Table 1 ). 
Table 1: Age Distribution of Study Population

\begin{tabular}{lcc}
\hline Age Group & Frequency & Percent \\
\hline Less Than 20 Years & 34 & 4.3 \\
20 to 30 Years & 449 & 56.9 \\
More Than 30 Years & 306 & 38.8 \\
Total & $\mathbf{7 8 9}$ & $\mathbf{1 0 0 . 0}$ \\
\hline
\end{tabular}

Mean age \pm SD (Range) $28.96 \pm 5.382$ (19 to 46 )

The mean with SD of sperm concentration before and after swim up method was $106.90 \pm 52.872$ and $54.20 \pm 30.368$ respectively. The sperm motility before and after swim up method was $54.11 \pm 15.629$ and $83.13 \pm 13.375$ respectively. The Sperm Morphology before and after swim up method was $58.10 \pm 7.749$ and $82.06 \pm 9.961$ respectively (Table 2 ).

Table 2: Mean with Standard Deviation of Different Parameters of Sperm Characteristics Before and after Swim up Method of Sperm

\begin{tabular}{lcc}
\hline Variables & Time & Mean \pm SD \\
\hline Sperm Concentration & Before & $106.90 \pm 52.872$ \\
& After & $54.20 \pm 30.368$ \\
Sperm Motility & Before & $54.11 \pm 15.629$ \\
& After & $83.13 \pm 13.375$ \\
Sperm Morphology & Before & $58.10 \pm 7.749$ \\
& After & $82.06 \pm 9.961$ \\
\hline
\end{tabular}

The mean changes of sperm concentration before and after swim up method was $52.70 \pm 42.88$ with the $95 \%$ confidence of 49.58 to 55.82 . The difference was statistically significant $(\mathrm{p}=0.000)$. The mean changes of sperm motility before and after swim up method was $29.03 \pm 14.849$ with the $95 \%$ confidence of 30.11 to 27.95. The difference was statistically significant $(p=0.000)$. The mean changes of sperm morphology before and after swim up method was 23.96 \pm 11.328 . The difference was statistically significant $(\mathrm{p}=0.000)$ (Table 3).

Table 3: Comparison of Changes of Sperm Characteristics Before and after Swim up Method of Sperm

\begin{tabular}{lccc}
\hline Variables & $\begin{array}{c}\text { Mean } \\
\text { Difference } \pm \text { SD }\end{array}$ & $\begin{array}{c}\mathbf{9 5 \%} \\
\text { Confidence }\end{array}$ & $\begin{array}{c}\text { P value } \\
0.000\end{array}$ \\
\hline Sperm Concentration & $52.70 \pm 42.88$ & 49.58 to 55.82 & 0.000 \\
Sperm Motility & $29.03 \pm 14.849$ & 30.11 to 27.95 & 0.000 \\
Sperm Morphology & $23.96 \pm 11.328$ & 24.79 to 23.14 & \\
\hline
\end{tabular}

Paired Samples Test

\section{Discussion}

Traditionally, the major focuses of fertility problems in the past have been the female partners. Infertility as a socio medical problem can be considered in
Bangladesh because male infertility adversely and negatively causes family unrest, multiple marriages, divorce and even sometime suicide. There are about three million couples in Bangladesh are infertile and it is increasing rapidly changing in socio economic norm. Unfortunately like other developing nations, wives in Bangladesh are mostly blamed albeit husbands are responsible for $60 \%$ happenings.

The earliest technique is conventional swim-up method $^{1}$. This technique is based on initial sperm motility and the surface of cell pellet. There is significant reduction in chromatin condensed spermatozoa because of many layers of cells in pellet, and the production of ROS because of close cell-to-cell contact, cell debris and leucocytes. This ROS causes lipid per oxidation of sperm cell membrane thus reducing percentage recovery of motile sperm ${ }^{3}$.

Another method that will improve the recovery of motile sperms is density gradient method in which ejaculate is placed on the top of the density media with higher density. During this procedure, all cells reach the semen sediment. However, the highly motile spermatozoa move actively in the direction of the sediment gradient and can therefore penetrate the boundary quicker than poorly motile or immotile cells, thus highly motile sperms cells are enriched in the soft pellet at the bottom ${ }^{4}$.

A Cochrane data-based review of 2007 of randomised control trials (RCTs) by Boomsma ${ }^{6}$ confirmed that no method of sperm preparation provided better cycle fecundity than others despite differences in sperm recovery ${ }^{1}$. The overall success rate of IUI is controversial and depends on several factors, but pregnancy rate ranges from $10-20 \%$. Several factors increased the likelihood of pregnancy, including woman's age, duration of infertility, method of sperm preparation, unexplained infertility, anovulatory infertility and addition of controlled ovarian hyperstimulation $(\mathrm{COH})$. The percentage of actual number of motile sperms in sperm preparation have positive impact while the presence of endometriosis, pelvic inflammatory disease (PID), and severe male factor have negative impact ${ }^{5}$.

\section{Conclusion}

There is a significant changes of quality of semen after swim up method during intrauterine insemination. The mean changes of sperm concentration, sperm motility and sperm morphology is statistically significant. Therefore the swim up method of semen is essential during intrauterine insemination. 


\section{References}

1. Bashed MA, Alam GM, Kabir MA, Al-Amin AQ. Male infertility in Bangladesh: what serve better-pharmacological help or awareness programme? International Journal of Pharmacology. 2012 Nov 15;8(8):687-94

2. Orbiclinic, 2011. Infertility in men is increasing. San Francisco, CA 94104, USA

3. Gaur, D.S., M. Talekar and V.P. Pathak, 2007. Effect of cigarette smoking on semen quality of infertile men. Singapore Med. J., 48: $119-123$

4. Bashed, M.A., 2011. Male infertility. Bangladesh Institute of
Medical Science (BIMS), Dhaka, Bangladesh. http://www.bims-bd.com/male_infertility.htm

5. Butt F, Chohan MA. Comparative efficacy of density gradient and swim-up methods of semen preparation in intrauterine insemination cycles. JPMA. 2016;66(932)

6. Boomsma CM, Heineman MJ, Cohlen BJ, Farquhar C. Semen preparation techniques for intrauterine insemination (Review).Cochrane Database Syst Rev. 2007;(4):CD004507

7. Henkel RR, Schill WB. Sperm preparation for ART. Repro Bio \& Endo. 2003; 1:108 